\title{
JARDINES: PASEOS POR LA MEMORIA EN CATALUÑA
}

\author{
Mª JeSÚS BuXó I REY \\ UNIVERSIDAD DE BARCELONA \\ ESPANHA
}

\begin{abstract}
La revitalización actual de las minorias étnicas y el interés constante de la Antropología por la etnicidad y la reinvención de tradiciones se han cruzado de forma fructifera para poner en evidencia la complejidad de los materiales y las formas expresizas que se usan para construir y experimentar la identidad cultural. Superada la consideración esencialista de la etnicidad, el énfasis se situa en la predilección y la selección de repertorios de la imaginación y la acción cuyos actores activan mediante la recreación de los significados, las imágenes, las ideas y los ideales inspirando los sistemas ideológicos, los movimientos estéticos y las prácticas de la vida cotidiana. El artigo se acerca de la identidad catalana através de la vinculación entre estética e identidad de que los jardines se assumem como exemplo.
\end{abstract}

The present resurgence of ethnic minorities together with anthropology's constant interest in ethnicity and in the invention of tradition have come together in a fruitful way clearly exposing the complexity of both the materials and forms used to build and to experience cultural identities. Having rejected an essencialist notion of ethnicity the emphasis is now put on the ability to prefer and to choose from a wide repertoire of action and of imagination, both activated by the social actors through the creation anew of meanings, images, ideas and ideals that will then act as inspiration for ideological systems, aesthetics and the practices of daily life. This paper approaches the Catalan identity througlt the relation between aesthetics and identity of which gardens are taken as an example.

En este marco, no cabe entender la identidad catalana como una representación colectiva o mentalidad estática y unívoca. Si bien esta concepción perdura en el discurso etnopolítico que gira entorno a un sentido étnico nacional y patriótico adquiriendo vigor social puntualmente en situaciones de enfrentamiento e imposición políticas, y de adscripción ideológica militante y electoral, lo cierto es que la identidad en Cataluña se ha mantenido y tiende a ser comunal o matriótica basada en la lengua, la historia, la literatura, la religión y los paisajes de tierra adentro y mediterráneos pero también de saberse una tierra de paso y pacto, de bilingüísmo histórico y de apetencias e incursiones estéticas e intelectuales más allá de sus propias fronteras culturales ayer y hoy.

En este sentido, son muchos los aspectos que pueden acercarnos a la identidad catalana, pero voy a destacar la vinculación entre estética e identidad por tratarse de un territorio suficientemente ambivalente en el que, mientras por un lado las normas ordinarias de la cultura parecen no aplicarse, por otro, genera mecanismos de validez intersubjetiva que se caracteriza por producir sentimientos y afectos que conducen a la sensación de la belleza como ideal compartido. De ello pueden derivar sensaciones de comunión, sentimientos de representación compartidos, de enlace social e identitario donde los individuos están libres de las restricciones ideológicas, económicas y políticas. Y esto es lo que actualmente se califica como la estetización de la práctica social para cimentar un proyecto de comunidad imaginada, crear la sensación de armonía social y mantener la unidad nacional. Lo cual también coincide en hacer del juicio del buen gusto una de las sensibilidades compartidas que definen la identidad burguesa.

Sin duda lengua y literatura han sido y son las dos expresiones culturales más evidentes de la estetización de la identidad étnica. Tanto la literatura histórica y de ficción, como la narrativa oral, la exégesis textual y la normalización lingüistica sirven de diversa manera para crear y socializar el sentimiento nacional así como instrumentalizar la consciencia de clase. Siendo 
ambas relevantes, sin embargo un tratamiento exclusivo no revela toda la complejidad de la eficacia estética en la activación sensorial e intelectual de la identidad. Conviene, pues, abrirse a otras expresiones culturales que no queden restringidas a la textualidad, aunque la contengan, de carácter visual, más implícitas y evidentemente menos estudiadas, como podría ser el teatro o la ópera, pero que aquí vamos a situar en la construcción cultural de los jardines.

El interés identitario de los jardines yace en el hecho de que no son simplemente un espacio visual del arte, sino un lugar estético donde el conocimiento y la experiencia culturales se entretejen para producir representaciones, narraciones y sensorialidades. Constituyen así expresiones culturales performativas que, como cualquier otro discurso, literario o pictórico, usan la naturaleza y la historia, la vida y la ficción para crear significados convencionales y marginales, activar la imaginación así como divertir los sentidos, entretener, impresionar y emocionar. Pero, además, en el jardín concurren eficacias estéticas adicionales en las que, al modo de un orden invisible, el aprecio y el gusto por lo bello hace que los actores queden sumergidos en la propia experiencia y olviden el interés y la finalidad con la que se inició por lo cual resulta ser un mecanismo de resolución tácita de problemas cuya especificidad reside en el hecho de que los fines se diluyen en la propia experiencia. Lo cual es aplicable al componente entre ilusorio y resolutivo de las identidades mediterráneas, todavía hoy intersticiales, sino marginales, que han tenido poca voz y concierto en conseguir el espacio político y a veces territorial que consideran legítimamente suyo, que incluso pueden perder en el plano de la razón, pero que, en cambio, siempre ganan en el plano de la estética, manteniendo viva $\mathrm{y}$ vigente su identidad, renovando reinventando $y$ en definitiva, celebrando su religiosidad popular, fiestas, literatura, urbanismo, paisajismo arquitectónico y jardines.

En tanto que representación, el jardín se asocia históricamente a lugares sagrados y de placer como el Edén y el paraíso persa que dan forma a los mitos de origen de las diferentes tradiciones judías, árabes y cristianas. Esto llena la ideación del jardín y sus conceptos de pregnancia simbólica que nutre los sistemas clasificatorios explícitos y tácitos respecto al bien y el mal, lo sagrado y lo profano, la vía interior y la exterior, la limpieza y la suciedad, el cielo y el infierno, la salud y la enfermedad, el premio y el castigo, el ocio y el trabajo, lo íntimo y lo externo, el alma sensitiva y el cuerpo, la identidad matriótica y el espíritu étnico o nacional. $Y$ a través de la contraposición, la reunión y la alternancia, estas polaridades permiten establecer nuevos órdenes para proyectar el control de la naturaleza y la sociedad mediante el mito y la ingeniería así como los símbolos de poder público y político. En el pasado, parques y jardines representaron el poder de reyes y nobles, pero también con el tiempo ha estructurado la transición democrática de lo privado a lo público del espacio urbano y las regulaciones sobre el orden público, la salud y la seguridad ciudadanas. $Y$ esto constituye a lo largo del siglo XIX y parte del $X X$ el discurso que todavía hoy caracteriza la identidad europea. 
Pero el jardín es un lugar de la memoria y la imaginación que va más allá y se interna en los espacios íntimos y secretos. Así, en el territorio de la experiencia, el espacio del jardín se convierte en lugar donde se cruzan y combinan las ideas estéticas y la sensorialidad en todas sus modalidades - visual, táctil, olfativa, auditiva -. Se trata del locus amoenus donde el son de los trinos, el murmullo del agua, la sensación del aire, la fragancia de flores y los arbustos, y el juego de luces y sombres de los árboles mecidos por el viento, crea un rico juego de asociaciones conceptuales y emotivas que abren los campos de evocación, la sensorialidad cenestésica, la ensoñación e incluso la transformación de la consciencia. En este sentido, la experiencia del jardín tiene una cualidad performativa o actancial que implican vicaria y virtualmente a los actores en la construcción de sensaciones y significados espontáneos, graduales y en diferentes claves interpretativas al modo de la ejecución de un instrumento corporal, según y a través de toda suerte de actividades: descansar, meditar, airearse, curarse, abrirse al deseo y la amenidad, ensoñar, ejercer la utopia, disfrutar de la privacidad y la sensación de secreto y también como marco donde presentarse socialmente para evidenciar el prestigio social.

Estos entresijos de la estética y la identidad a través de los jardines están bien expresados y relatados en las artes literarias, novelas, cuentos y utopías, en la narrativa musical y pictórica, en el discurso y en el diseño profesional de los jardines así como en la jardinería doméstica. $Y$ en este sentido, propongo un paseo rastreando algunos aspectos históricos y etnográficos de la construcción del espacio- y la experiencia sensorial de los paisajes y los jardines en la Cataluña industrial de mediados y finales del siglo XIX y también la primera parte del siglo $X X$ extraídos del Archivo Histórico de Sabadell y una larga experiencia etnográfica hecha de espacios personalmente vividos $y$ otros espacios recorridos con informantes mediante el paseo, el recuerdo y la narración en las zonas de Sabadell, Castelltersol y Matadepera.

\section{JARDINES EN LA HISTORIA E HISTORIAS DE JARDINES}

En toda Europa, la confluencia del Romanticismo y la industrialización produce una relectura de la relación cultura y naturaleza cuyo símbolo dominante es, en mayor o menor grado y según los paises, el paisaje de los jardines. No se trata ya de los grandes parques aristocráticos del XVII y del XVIII, sino que, desde el Congreso de Viena en 1814, los jardines en sus diferentes versiones, francés, inglés, italiano o vienés, entran en un discurso estético relacionado con la conceptualización de la identidad nacional, con la ideación de una nueva imagen de la burguesía y la consideración de las condiciones técnicas y sociales de la modernización.

Se observa así que el sistema clasificatorio del jardín es per se indicativo del reconocimiento de la vinculación entre nación y estilo de jardinería lo cual va a motivar preferencias y afinidades entre el discurso étnico y la práctica de la jardinería. Lejos de ser universalmente válidos, las expresiones metafóricas y simbólicas de los jardines 
también dependen del grupo social al cual los actores pertenecen formándose repertorios de buen gusto y distinción que les clasifica en su posición social, la educación e incluso el sector comercial o industrial. $\mathrm{Y}$, por último, la industria y la urbanización crecientes generan condiciones de insalubridad y numerosas enfermedades asociadas a la contaminación de los humos de las fábricas, la falta de higiene y la carencia de espacio vital a lo cual se añade la inseguridad ciudadana derivada de la pobreza y la politización sindical. Esto plantea la necesidad de crear nuevas condiciones de vida pública para, por una parte, mejorar el aire de las ciudades y prevenir las enfermedades y por otra, siguiendo el discurso higienista, oxigenarse y pasear lo cual no sólo influye en la curación sino en activar la moral personal y el sentido cívico.

Ahora bien, ¿cómo se seleccionan y encajan estas ideas con el paisaje y el diseño de jardines en la construcción del discurso identitario en Cataluña?

\section{IDEACIÓN IDENTITARIA DEL JARDÍN}

En la Cataluña del siglo XIX, excepto por los jardines de claustro, algún que otro jardín aristocrático como el romántico jardín del Laberinto de Barcelona, los breves jardines de masía y los jardines indianos, el interés y la producción de parques y jardines es escaso en comparación con otras capitales europeas. Sin embargo, su desarrollo a finales y al cambiar el siglo, sigue vericuetos culturales complejos marcados por la internacionalidad de los diseños y el esfuerzo por crear alternativas propias vinculadas a diferentes conceptualizaciones de la identidad étnica.

A lo largo del siglo XIX predomina la idea del paisaje por encima de la del jardín. Por el alejamiento progresivo del mundo rural y la urbanización creciente, en el paisaje coinciden los tropos estéticos y utilitarios de la mayor parte de las expresiones y convenciones artísticas e intelectuales así como las fantasías referenciales de las ideológicas del poder. Tanto los que enarbolan la bandera política como el rezo religioso y las representaciones pictóricas y literarias usan las imágenes del paisaje catalán, montañas, ríos, tierra y aire, y las ungen de significación espiritual, de reverencia y autoridad moral. Como es bien conocido, la mayor parte de las analogías remiten a la Edad Media e idealizan viejos héroes así como la dignidad de la vida rural y las labores del campo. Se patrocina el espiritualismo religioso a base de metáforas sobre la fuerza y la grandeza de la naturaleza representada por las montañas y el contacto con el horizonte infinito que permite comunicarse con Dios y reafirmar simultáneamente la identidad con la tierra y el grupo. Serán Balmes, Verdaguer, Mañe y Flaquer quienes con su poesía y discurso político-social establecen un fuerte vínculo entre naturaleza, ideas religiosas $y$ nacionalismo. En el ámbito educativo se estimula el gusto y el sentimiento por el paisaje propio mediante el excursionismo científico que promueve la arqueología, la etnología y las ciencias naturales, lo cual queda reflejado en las publicaciones de las Memorias de la Asociación Catalanista de Excursiones Científicas (Valls i Vicens, 1877). 
Si enfocamos históricamente las ciudades del cinturón industrial de Barcelona, Sabadell y Terrassa, a mediados del siglo XIX, se produce un rápido crecimiento en la construcción de molinos y vapores, fábricas y tintorerías que se acompaña de un importante incremento demográfico y urbanístico. El paisaje es todavía entre urbano y campesino, entre fábricas y huertos de manera que el campo se entremete en algunas calles dejando uno o dos árboles que sirven de placita y rincón recoleto. No es hasta la segunda mitad del XIX que los alcaldes empiezan a preocuparse por la salubridad de las ciudades industriales, y se emprende el trazado, la construcción de las cloacas, los lavaderos públicos, la iluminación con fanales de aceite, la alineación de las calles e incluso plantar algunos árboles en las nuevas Ramblas (Carreras Costajussà, 1932).

Pero todavía no es tiempo de jardines públicos, trayectoria que en Barcelona se inicia con el Plan Cerdà cuyo fin es reverdecer $y$ airear la ciudad a base de jardines en el interior de las grandes manzanas, los pasajes y las avenidas en el área del Eixample. Estas preocupaciones se materializan con la creación de los primeros jardines públicos como el parque de la Ciudadela cuyo concurso de obras fue ganado por Josep Fonseré en 1872 siendo el lema del proyecto: "los jardines son a las ciudades lo que los pulmones al cuerpo humano". Gaudí participó en las obras del parque de la Ciudadela y más adelante en otros proyectos tangencialmente relacionados con la ideación de la ciudad jardín aunque bajo su especial rúbrica modernista. Aunque posterior, de este autor cabe recordar el Parque Güell, donde entreteje $y$ simula naturaleza $y$ arquitectura en troncos de piedra, flores de cerámica, y mil guirnaldas de azulejos. Así, salud y seguridad van unidos en la recreación de los ideales urbanísticos de la ciudad jardín que en Cataluña quedan influidos por los vieneses Wagner y Stübben y el inglés Howard.

Ya bien entrado el siglo $X X$, la influencia de Le Corbusier, aunque con diseños de horizontalidad $y$ verticalidad distintos $y$ trasfondos ideológicos contrapuestos, sigue incidiendo en la combinatoria de aire puro, salud e identidad lo cual se expresa mediante la apertura de espacios y cinturones verdes que permitan airear, ventilar $y$ reducir el polvo de la ciudad.

Unos por razones utilitarios y otros estéticas, o ambas, se coincide en poner de nuevo la naturaleza en las calles como alternativa al urbanismo generado por la revolución industrial. En el territorio de las artes, esto se expresa inicialmente mediante la recreación de la naturalidad cultural to cual se denomina Modernismo que propugna la pintura a pleno aire, la palabra viva en jardines refinados o en pueblos cuyo paisaje mediterráneo es en sí mismo un jardín. $Y$ de este aire mediterráneo del buen vivir entre el mar y el cielo parten los elementos estéticos constitutivos de la revitalización de la identidad cultural y de un nacionalismo hecho de la tierra y de sus paisajes que estos autores piensan en sus obras en el marco expresivo de los jardines. Son representantes un nutrido grupo de artistas que han sido denominados "bohemia dorada" por vivir temporalmente en Montmartre y codearse con los poetas simbolistas y el impresionismo pictórico y musical francés. Organizan fiestas al 
aire libre y estrenan obras de teatro y piezas musicales cuya temática hace referencia a los jardines. De Granados es poco conocida una pieza breve titulada $E l$ Jardín y también una suite sin concluir bajo este mismo título. Albeniz, Granados, Mompou buscan la belleza en aires musicales populares que unen la recuperación del patrimonio melódico con la renovación del gusto musical en términos internacionales. En el ámbito de la pintura y la literatura, Rusiñol recorre España pintando jardines y escribe en aucas teatrales sobre el jardín a modo de metáfora para reflejar los contrastes de sensibilidad y vulgaridad que representan el enfrentamiento entre lo auténtico, sea el hombre del campo, el burgués de clase, el trabajador honrado, y la vulgaridad o el darse aires de la pequeña burguesía de nuevos ricos. $Y$ otros muchos autores, Folch i Torres, Victor Català, hasta bien entrado el siglo XX, Rodoreda, hacen del jardín, la torre y la casa de campo el escenario ideal donde situar a sus personajes y ambientes en Cataluña.

En Alemania, en repuesta a la industrialización y a la situación política después de 1871 nace una nueva clase alta-media que también tiene interés en poseer jardines tipo villa. Esto incrementa simultáneamente el interés por la arquitectura de jardinería que une diseño, ciencia e ideación sociopolítica (Lange,1900 y Seifert, 1930). Así, la ideación del jardín naturaleza se vincula a las teorías de Darwin, el Nacional Socialismo y los escritos de Goethe. A través del jardín crecen las analogías entre ética y ambientalismo, el aire puro y libre que dará lugar a la metáfora política de la Volk-nationalistic ideology.
Con lentitud en Cataluña, el jardín burgués urbano se va alejando estéticamente del paisajismo romántico, religioso y ruralizante, y se seculariza vinculándose a la privacidad y la exclusividad social de la casa burguesa y a las expresiones modernistas del art nouveau. En las áreas suburbanas de Barcelona se construyen torres en las que el jardín condensa los símbolos del estatus y prestigio sociales con la ostentación y el gusto de época. Hay documentos que hacen referencia a esos jardines que así son descritos por el paisajista inglés Nichols, (1924):

"delightful gardens near Barcelona, as it includes more extensive suburbs than any other city in Spain, and almost every house has a fountain, and a pretty parterre of flowers, often showing taste and originality in its arrangement. Number of good examples are at Sarria and Horta".

Jardines de parcela que se extenderán a otras áreas de veraneo como Camprodón, Viladrau, Castellterçol y Matadepera, entre otros muchos lugares con mezcla de diseños pero con predominancia del estilo inglés, lo cual no deja de sorprender cuando ya Europa está en pleno apogeo el movimiento funcionalista. Esto impacta con fuerza, aunque en forma y función reducidas, en las casas de planta baja urbanas y suburbanas, tanto en la primera vivienda como en la de veraneo que siguen con la tradición de construir o mantener un jardín anterior o posterior como todavía se puede ver en Alella, Caldetes, Camprodón, Puigcerda, y en otros muchos lugares de Cataluña.

Enlazado con el modernismo, pero en evolución, a veces en contra por su dejo romántico, costumbrista y sentimental, pero. 
siempre en simpatía con la idea de construir una identidad y una nación fuertes, a partir de 1906 se produce un nuevo movimiento estético y ciudadano denominado noucentismo. El proyecto noucentista se propone introducir la objetividad científica y el realismo político: actuar desde fuera y acercarse desde la distancia a la realidad imponiendo inteligencia en el marco de los acontecimiento políticos del siglo XX. La analogía política de la mediterraneidad es la ciudad y la civilidad lo cual se expresa metafóricamente a través de la belleza pública constituida por el orden, la pureza y la luz. Por primera vez, se plantea la arquitectura de jardines como un bien público y con este fin se funda en 1917 la institución de Parques y Jardines, dirigida por Rubió i Tuduri para crear y arreglar los jardines de la ciudad.

Ya se ha indicado que la vinculación jardín, ideología política e identidad étnica no constituye un movimiento aislado. Aunque de forma diversa, se conecta o se contrapone a diferentes corrientes centroeuropeas, británicas y francesas. Así el noucentisme para distinguirse del modernismo catalán que considera vago, difuminado y romántico, se asocia con la tradición germánica aunque también aplica diseños del paisajismo inglés, pero también se mira en otros aires mediterráneos que le enlazan con el movimiento de recuperación del clasicismo mediterráneo en el sur de Francia. Procedente del simbolismo poético, Jean Moreas, un poeta de origen griego, se propone devolver a la literatura el aire del mediterráneo, el azul del mar $y$ el sol. Hay en su programa una invocación al provenzalismo de Frederic Mistral quien ya había hablado de raza latina a finales de siglo, y que hace del mediterráneo un mundo de aire denso y de aires en el que todos los sentidos se despiertan. $Y$ para fundamentar étnicamente este programa poético, Moreas funda l'Ecole Romane française que reivindica la defensa del alma latina fuera de toda ingerencia germánica. Esto es,lejos del pesimismo, la oscuridad y la melancolía del romanticismo y más concretamente de las brumas sajones y las nieves germánicas, se busca encontrar el fondo de las claridades griegas para formular un ideario mediterráneo. $Y$ un paso político más en esta dirección es la fundación de la Acción Francesa en 1899 cuyo iniciador, Charles Maurras, se propone mediterraneizar la política para lograr la unidad moral de todos los pueblos mediterráneos (Vallcorba, 1994). De los contactos personales con este grupo poco sabemos, pero lo cierto es que el movimiento noucentista asienta en la mediterraneidad los tropos dominantes de la catalanidad en su doble dimensión clásica y cívica: Grecia y Roma y la ciudad ideal. Así la Cataluña ciudad es la base metafórica para construir el país (el paisaje) y desarrollar una vida (un jardín) civil íntegra y moderna.

La mediterraneidad alcanza su máxima expresión en el ideario de Eugeni d'Ors quien afirma que sus ideas no se dirigen a los sentidos, sino al interior de la razón y la inteligencia. Si el impresionismo traducía la realidad sin depurar la sensación que recibia, ahora conviene saber orientar la sensibilidad hacia un orden, esto es, pasar del impresionismo al estructuralismo, de ahí que se critique el plan urbanista Cerdá y la arquitectura modernista por fantasiosa $y$ desorientadora. Este clasicismo intelectualista 
quiere reelaborar la naturaleza idealizándola pero de forma controlada ya que los valores culturales están por encima de la libertad de los valores naturales. Asimismo, Ors dedica varios artículos a cómo deben ser los jardines. Así escribe en "La jardinería moderna" (1907) que los jardines no deben ser ingleses, imitación del bosque, ni alemanes, románticos, sino que, aunque respetuosos de la libertad de la naturaleza, conviene volver a lo clásico y a la Ciudad que son el punto de inflexión donde la Naturaleza es vencida por la fuerza de la convención y la solidaridad.

Otro noucentista, Folch i Torres, también en dos artículos "Jardincitos de Masía" (1915) y "Notas sobre el arte del jardín" (1916), explica que el jardín catalán es un jardín cerrado, una transformación del patio, un entremedio entre la arquitectura y el paisaje. A cuya definición añade que la impresión que producen la visión de uno de estos pequeños jardines lleva el espíritu todavía más hacia el origen de las cosas mediterráneas.

\footnotetext{
"El ejercicio de ordenación de la naturaleza, y el jardín permite conectar con el paisaje genuino de los bordes mediterráneos". "Y este es el jardín que hemos de construir ahora. El Jardín civil embellecedor de nuestras perspectivas, armonioso con el conjunto urbano, y hacia él hemos de ir sin otro deseo que el de exaltar, de dar cuenta de la belleza de nuestra naturaleza con los elementos de estos jardines populares, que son la flor exquisita de esa naturaleza."
}

Esta construcción ideativa guía las expresiones estéticas y confluye con los planteamientos ideológicos y políticos del gobierno catalán de la Mancomunidad desde 1910 sin decir cabe de los intereses de la burguesía nacionalista. $Y$ de esta relación y vinculación con intelectuales y artistas se define $y$ difunde un proyecto ideológico de modernidad orientado a innovar el diseño urbanístico y arquitectónico. La innovación se apoya en una estética que busca sus analogías en la simplicidad, la pureza, la armonía, la medida, la concreción, la estabilidad y el gusto por las cosas sencillas y se concreta en metáforas de civilidad cuyo fin es mejorar y crear condiciones adecuadas de aireación en las infraestructuras hospitalarias, viviendas, fábricas y colonias industriales, así como en toda clase de edificios oficiales desde las escuelas a los museos.

El paisaje cultural mediterráneo se convierte así en el idioma oficial y el jardín es una expresión personal de esa identidad con lo cual la expresión política más relevante es el jardín público. Eran pocos los parques que había en Barcelona, y ahora con motivo de la segunda Exposición Universal, le toca a Montjüich. En 1915 se invita a un arquitecto francés, Forestier quien con Rubió i Tudorí, urbanista y difusor del ideal mediterráneo, ajardinan la montaña de Montjuich. Forestier aporta el diseño de jardín francés clásico pero activo: no para mirar sino para usar y vivir; y Rubió teoriza sobre el jardín latino, paisajístico pero no romántico, un espacio para establecer el contacto con la naturaleza y conseguir belleza, higiene $y$ bienestar para la población, y a la vez constituir un signo de identidad.

De igual modo que el espacio externo de las calles, avenidas y parque se ilumina con nuevos diseños de arbolado, parterres y jardineras, también el diseño interior de edificios y casas se 
abre a una decoración floral en cristales y azulejos en busca de la luz y la transparencia hasta el extremo de simular un jardín. Un preludio serían los cristales y azulejos florales del Palau de la Música Catalana donde entre guirnaldas de flores surgen damas virtuales que parecen volar o salir de las paredes mientras los caballos en escorzo parecen brincar en el aire mítico de la música. En los pisos del Eixample, se decoran interiores con galerías ajardinadas mediante motivos florales en las cerámicas, las maderas y los cristales como todavía puede verse hoy en la casa Batlló y la casa LLeó del Paseo de Gracia. Los residentes del principal tienen acceso a un jardin posterior bien sea directamente o bien a través de una escalera, o a una terraza ajardinada. Más adelante, yendo en busca de una mayor luminosidad y aireación en detrimento de la contaminación urbana que suma el humo de las fábricas al de los coches, la arquitectura urbana mira más arriba, de forma que los primeros pisos y patios pierden el favor por los áticos ventilados desde donde se vislumbra otra ciudad, y ahí se construyen terrazas ajardinadas siendo su expresión más elaborada la terraza colgante. En este proceso de ir hacia arriba son de gran interés los jardines colgantes de la Casa Cambó en Vía Layetana. Según cuenta la historia, el político Cambó viajó a Nueva York a principios de siglo y vio los roof gardens de la Quinta Avenida, de forma que en 1925 encargó a Forestier y a Rubio i Tudorí que le proyectasen un jardín encima de la casa en el más puro estilo de McKim, Mead y White.

\section{JARDINES QUE NOS HABITAN}

Más allá de las influencias internacionales y las formas de entretejer la ideología y la estética en la construcción de la identidad en Cataluña, los jardines ofrecen otras dimensiones menos explícitas aunque muy sugerentes de cómo los jardines habitan en los actores y cómo estos negocian los significados, juegan sus sensaciones y. desvelan sentimientos identitarios o simplemente aspectos emotivos de la vida cotidiana. Así, la transformación de esos espacios ideativos en lugares culturales vividos aporta datos sobre la experiencia de clasificar lo privado y público, el buen gusto y la moda, elaborar narrativas familiares y políticas sobre la identidad étnica, de clase y de género, así como invertir aspectos del orden doméstico abriendo la sensación de libertad de acción y recreando la sensorialidad del cuerpo. Para iluminar esos intersticios donde se recrean estéticamente las identidades, voy a considerar aspectos etnográficos procedentes de relatos sobre la vida en el jardín de diferentes familias burguesas y obreras en la ciudad de Sabadell.

A finales del siglo pasado, todavía no es época de jardines y la burguesía comercial e industrial se mueve entre dos espacios que nutren el gusto por el paisaje y que ya anticipan el jardín. En el interior de las casas, la decoración vinculada al Art Nouveau se llena de vegetación con motivos florales y guirnaldas que adornan las paredes pintadas y las tapizadas en seda así como las cerámicas que cubren las paredes y las cristaleras de las galerías y las entradas. No suficiente con ello, las pinturas que cuelgan de esas paredes también expresan el gusto por el paisaje y el bodegón, lo cual se extiende al diseño y grabado de las vajillas, cristalerías y cuberterías, al estampado de las indianas y a los bordados de mantelerias, sábanas y ropa interior, 
constituyendo signos de distinción, prestigio y respetabilidad.

Esta preferencia estética por el paisajismo y lo vegetal, se extiende al paisaje real de las propiedades en el campo, sea casa pairal, masía o torre. Ahí, el jardín dispone, por pequeño que sea, de un safareig o estanque rodeado de macetas con flores diversas. A veces se forman parterres que rodean un pequeño surtidor o simplemente rodean la casa y las escaleras. $Y$ esto se extiende al huerto de vegetales y de árboles frutales hasta confundirse con la arboleda del bosque. A la casa de campo se acudia a cambiar de aires, a descansar, a convalecer de enfermedades, a veranear y a relacionarse socialmente. Tanto en la literatura como en las versiones orales, se describe como una vuelta a la vida rural de la masía, la vuelta a la paz del paisaje poético, el aire libre y puro, y al encuentro con las propias raices. Tradición $y$ naturaleza romantizan los origenes $y$ legitiman lo primigenio: recolectar setas, ir a cazar, beber agua de las fuentes y comer fruta de los árboles. En este discurso, la recreación de lo saludable se contrapone a la insalubridad y la contaminación de la ciudad por los humos y los vapores, y también por otros peligros como la inseguridad ciudadana derivada de la agitación obrera.

Tan pronto se pasa al jardín de parcela, tipo villa, no sólo se expande la experiencia imaginativa privada, sino que sirve como prolongación, al modo de una mise en scene, del poder económico y las pretensiones sociales de sus dueños. Esto es fácilmente observable en la calidad y la ornamentación de tapias y verjas así como en el estilo y las funciones del jardín
El jardín representa la posición social pero ésta queda modulada por la interrelación entre moda o gusto de época y las preferencias y el estilo que aporta cada familia según se sigan patrones de jardín francés, italiano, inglés o mediterráneo. A esto se suman otros ingredientes como la disposición de los elementos decorativos y el uso social del jardín. Sobre el primer punto son relevantes la disposición de los árboles y los parterres de flores, los tipos y la coloración de las flores, las fuentes, los surtidores o los estanques con flores y peces, las glorietas y las pequeñas grutas donde colocar faunos o vírgenes. $Y$ sobre el uso familiar $y$ social se distinguen lugares, actividades y repertorios, con temporalidades y recorridos diversos los festivos y los días comunes según las estaciones. Así, la rosaleda y el paseo a la glorieta tiene sus mañanas de niñeras y niños, sus aperitivos y tardes para los mayores, y la nocturnidad de los novios y el servicio doméstico. A diario, en primavera y verano, las mujeres cosen y doblan ropa en el jardín y ahí mismo se reza el mes de Maria, pero ese misma zona sirve para fumar después de cenar y para toda suerte de celebraciones familiares, bautizos, comuniones y peticiones de mano.

A medida que el jardín va adquiriendo protagonismo social, se produce un cambio estético substancial modificándose la decoración interior desde la ornamentación recargada de los tapizados, las pinturas de bodegones y los tapices con representaciones históricas o literarias, hacia un nuevo tipo de sensibilidad decorativa. Se dan diferentes explicaciones, sea la pérdida de las colonias de América, el cambio de siglo, o simplemente la 
modernidad, lo cierto es que las paredes se aclaran $y$ se añaden al patrimonio familiar mapas antiguos $y$ nuevos $y$ fotografías ricamente enmarcadas compradas y hechas con motivo de las exposiciones universales y los viajes realizados al extranjero durante la luna de miel o por motivos comerciales.

Se presenta así una forma tecnológica de ver el territorio físico propio y ajeno, recalar la identidad familiar en las imágenes fotográficas de diferentes generaciones en situaciones rituales, comunión, bodas y competir en distinción social con innovaciones tecnológicas mobiliarias como el teléfono, la radio y el gramófono.

De los barrios menestrales cabe recuperar la organización del espacio urbano desde la sencilla casa de soportal a la llamada casa de cuerpo y, progresivamente, la casita inglesa de planta a la que luego se le agrega el piso superior. En Sabadell, estas viviendas se extendían de forma irregular aunque cada una de ellas sigue un patrón interior semejante. A partir de la puerta de entrada sigue un pasillo que a derecha o a izquierda, o a ambas según el nivel económico, da acceso a las habitaciones, unas con ventana que da a la calle y las demás ciegas, y ese pasillo termina en el comedor y la galería. Cuando todavía la parte posterior daba al descampado y no se había cerrado el patio con paredes medianeras, a ese espacio entre dos casas se le denominaba androna, o lugar donde se reunían los hombres a charlar. Sea en las afueras de la ciudad, o en esa parte posterior de la casa, la experiencia de trabajar el campo, o hacer un huerto, no está lejanra en el tiempo se sea del lugar o inmigrante, e incluso los que trabajan en las fábricas y talleres según las épocas del año todavía colaboran en las tareas de cultivo y recolección en las propiedades de los dueños de las fábricas. Al construirse progresivamente las paredes medianeras se delimita un patio o jardín que se llama eixida del latín exire o salida, algunos con acceso directo a la calle mediante una puerta pequeña y otros no. Al cerrarse la eixida también se abre y prolonga la casa en forma de galería y ésta inicia la transición hacia la parte más luminosa y ventilada que, con frecuencia, es decorada a modo de preludio con cerámica hasta media pared con diseños florales que también se repiten en los cojines de cretona floreada de sillas y tapetes, marcos con formas vegetales, calendarios de cartón recortados en relieve con flores $y$ pájaros. $Y$, según la posición económica, también la puerta que da al jardín esta decorada con algunos cristales en forma de vegetación.

Existe abundante documentación de archivo sobre la evolución de estas casas y la historia oral así como los relatos actuales permiten documentar el uso que se hacía de la galería y el jardín hasta hace relativamente poco. La galería actúa como una preparación, como un preludio floral, desde donde cruzar el dintel para acceder a la eixida. Al entrar en el jardín se produce un efecto semejante a la inversión perceptiva del orden de las cosas que sucede cuando Alicia en el País de las Maravillas cruza el umbral del espejo. Se entra en un mundo sensorial en cuyo aire se mezclan los olores humanos, animales y vegetales, en un hortus concluso íntimo y alejado de otras miradas lo cual contribuye a invertir el orden doméstico y corporal. Si el interior representa el control, en 
la eixida se rompen las convenciones exteriorizando todo aquello que dentro esta restringido lo cual lo convierte en lugar de placer, alegría, bienestar, tranquilidad e incluso sensación de libertad.

Son elementos de ese abigarrado mundo interior exteriorizado la comuna de tapa redonda, el pozo, el lavadero, el tendedero, la jaula del jilguero o canario, el gallinero, y en un rincón excremento animal acumulado para abonar las plantas, hacer un poco de huerto $y$ por doquier profusión de flores en simples parterres, en potes, cubos y en cualquier otra recipiente. Ahí se airean acciones diversas como ventosear, fer pets y erutar, fer el rotet, después de comer y también salir a fumar. Se invierten el control y los hábitos sociales del cuerpo en la dirección de la desnudez y el contacto con el agua ya que el lavadero se usa para lavar, lavarse y refrescarse en verano. Se liberan también tabúes visuales respecto a prendas, fajas, calzoncillos, y otras prendas interiores que cuelgan invertidas ventilándose $o$ secándose al sol. $\mathrm{Y}$ se airean otras cosas, las risas y gritos en el juego de los niños, los susurros de los enamorados y la hilaridad y el comentario secreto de los mayores. Al airearse intimo del patio se contrapone la sociabilidad de cotillear por encima de la medianera con el vecino aunque la práctica más frecuente en las calurosas noches de verano consista en sacar sillas a la calle y ahí conversar y mirar a quien pasa. No hay que olvidar que la eixida también es parte importante del discurso de sanación lo cual se extiende a las prácticas curanderas. Según cuentan actuar en el patio resulta más eficaz para curar d'aneigat, los celos, el mal de ojo, la desgana, la debilidad y la ansiedad ya que se trata de un espacio mágico, como el bosque, por concurrir todos los elementos: aire, tierra (hierbas del bosque), agua (lavadero) y fuego (fogón de leña donde calentar el agua para lavar). De ahí la eficacia simbólica del jardín que hace que a través de su contacto o paso, los hechos y las cosas se inviertan, transformen $y$ reintegren entre sí. Así las cualidades de bueno y malo, limpieza y suciedad se relativizan en el proceso de reintegración de sus elementos en la naturaleza como lavar, lavarse y regar, curarse, abonar con excrementos las plantas e improvisar un cementerio de animales domésticos al fondo del jardín.

En la eixida se representa y experimenta otra relación entre naturaleza y cultura: se recrean las identidades, sea el origen rural, la adscripción ideológica de clase y la etnicidad. En este espacio se vivifica el viejo lazo con el origen campesino familiar y el pueblo, sea local o por inmigración, mediante el trabajo de la tierra pero también del intercambio entre parientes $y$ vecinos de plantas y esquejes, e incluso a veces un poco de tierra procedente del pueblo, o simplemente hierbas del campo o del bosque más cercano. La eixida como analogía del campo representa la tradición familiar del pueblo, pero también incorpora el ideario anarquista de amplia difusión obrera metaforizando el microcosmos de una comunidad natural a través del cultivo de los ajos, la desnudez, el lavarse, la unión libre, la vida sana y la libertad de expresión. Y, por último, cabe destacar el jardín como zona secreta de libertad donde encauzar la inspiración poética tanto en relación con los poemillas de navidad y amor escritos bajo el almendro o junto al rosal 
creando metáforas que evocan sus devociones, amores y creencias, como para expresar la represión de la lengua catalana en diferentes momentos de la historia, y con ello animar y nutrir sentiméntalmente la consciencia étnica. Así mientras en las escuelas se imparten las clases y se lee en castellano, en el jardín y en la patio de la escuela se habla y se juega en catalán, y de igual modo el jardín o l'eixida de las casas se convierte en el paisaje donde se conserva secreta y celosamente la identidad étnica.

\section{Del JARdín DE RETAguardia AL GaRden CENTER}

Los cambios políticos de la Dictadura de Primo de Rivera (1923-30),y más tarde la guerra civil del 36, fueron épocas de pocas razones y estéticas. Interrumpido todo por la guerra, muchos jardines se convierten en huertos de retaguardia donde cultivar patatas y hortalizas y el mensaje estético noucentista se dispersa en el exilio exterior mientras en el interior va decantándose por las tendencias avant-garde de Europa.

Durante muchos años después de la guerra, según cuentan mujeres de edad de Sabadell y Terrassa, la sensación era como si los jardines y las eixides se hubieran quedado sin aire, dentro de un largo invierno, uno igual a otro, con mucho frío, poca luz y nada para invertir en arreglarlos. Lentamente la burguesía vuelve a contratar a los jardineros para poner remedio al aspecto anticuado de parterres hechos de roca simulada, glorietas deslucidas y fuentes $o$ grutas de inspiración religiosa. Así, los jardines de ciudad van adquiriendo un aire más funcional mientras que en la torre o casa de campo se sigue la moda del jardín paisajístico o inglés, incorporando el césped como la expresión estética de mayor gusto y prestigio social.

En 1945 vuelve del exilio Rubió i Tudurí y dentro de las tendencias del paisajismo como modernidad que intenta armonizar o enlazar el espacio interior de la casa con el espacio exterior del paisaje, este diseñador realiza jardines privados y hoteleros buscando la apariencia de naturalidad mediante la apertura visual, la transparencia y el dinamismo de árboles, flores silvestres y riachuelos, siempre de acuerdo con el paisatge nostrat, o naturaleza que considera propia y del espíritu mediterráneo o latino.

En las eixides, más humildes, también se renueva el ropaje vegetal y se llenan de rosales y bulbos, muchos de éllos ahora comprados a través de catálogo. Estos patios empiezan a recortar su espacio bajo la tendencia de la remodelación interior la ampliación de baños y garajes, y otros van desapareciendo bajo el nuevo urbanismo y la especulación que transforman el paisaje de casa unifamiliares en viviendas de pisos. Si bien se abren nuevos barrios por el empuje de la inmigración de los años 1950, a pesar de la regulación de los permisos de obras, el barraquismo o los llamados albergues de urgencia tienden a la extinción de la eixida que con frecuencia queda reducída a un patinillo de ventilación. Con la verticalización de la ciudad, el jardín se traslada progresivamente a la segunda vivienda, de 
veraneo o de fin de semana, tanto en las antiguas como en las nuevas casas de parcela, chalets, torres y, más adelante, al escaso espacio de las casitas pareadas y las jardineras de las terrazas.

Si en el pasado estética e identidad se vincularon a través del paisaje y el jardín para crear sentimientos y voluntades alrededor del gusto por las raices, las virtudes y los valores propios, creando la comunidad imaginada que las diferentes condiciones sociopolíticas negaron a Cataluña. Ahora la revitalización étnica factible en el jardín no encuentra en la mundialización y las tendencias postmodernas el mismo amparo en unir estética e identidad de manera que, a pesar del esencialismo etnopolítico, la representación y la experiencia identitaria aún referenciándose en el paisaje y los jardines ha modificado su registro y clave como lugar de la memoria y del imaginario. Ciertamente la identidad se sigue referenciando en los paisajes propios, pero el registro es ecológico, lo cual implica interferencias ideológicas de diferente signo y la clave es consumista lo cual entremezcla el excursionismo con el deporte de aventura y la denominación de origen de los productos folclóricos y alimenticios con el consumo turístico. De igual modo, los jardines de segunda vivienda, en la playa o en la montaña, representan una nueva estética social que combina la barbacoa familiar y social, las plantas exóticas, las hierbas locales para sazonar y el riego automático, todo comercializado en los garden center colocados estratégicamente en las carreteras a las entrada y salida de los pueblos y las ciudades. Además, el hecho de que a menudo se haya impuesto un urbanismo de urgencia, es decir, sin consideraciones ni previsiones, ha llevado muchas veces a arbitrar la creación de superficies asfaltadas -plazas duras- de mero tránsito cuya escasez arborea no favorece ningún discurso identitario excepto el que los intereses y las electorales imponen. $Y$ otras innovaciones como el aparcamiento de los centros comerciales que los domingos cumple la función del paseo y el entretenimiento familiar que en otras épocas tuvo el parque público.

Como señala Goody en su libro sobre $L a$ cultura de las Flores (1993), las flores y el jardín han pasado a formar parte del consumo masificado, $y$ en ese sentido aportan nuevos datos que distinguen a ricos y pobres, el buen y el mal gusto así como expresiones culturales vinculadas a la diferencialidad étnica, pero ahora entendida multiculturalmente como la reinvención y la mezcla de tradiciones $\mathrm{e}$ innovaciones mediadas por la propia mundialización. 


\section{BIBLIOGRAFÍA}

\section{CARRERAS COSTAJUSSÀ, $M$.}

1932 Elements d'Historin de Sabadell, Edicions de la Comissió de Cultura, Sabadell.

\section{FOLCSH I TORRES, J.}

1915 Jardinets de Masia. La Veu de Catnluntya, Pàgina artistica, Barcelona.11 de gener.

1916 Notes sobre l'art del jardí. La Veu de Catalunya, Pàgina artística. 21 de febrer.

\section{GOODY, JACK.}

1993 The culture of flowers. Cambridge, Cambridge University Press

\section{LANGE, $W$.}

1900 Garten und Weltanschauung. Gartentoelt, 4, 361364.

MISTRAL, F.

1957 Calendau en Obras Escogidas, Madrid, Aguilar.

\section{NICHOLS, R. S.}

1924 Spanish and Portuguese Gardens. Boston, Houghton Mifflin C.

D'ORS, E.

1907 La jardineria moderna. La Veu de Catalunya, 14 de mayo.

1980 La Ben Plantada. Barcelona, Selecta.

\section{ROVIRA I VIRGILI, A.}

1966 Els corrents ideològics de la Renaixenţ̧ Catalana.

Barcelona, Minerva.

\section{RUSIÑOL, $\mathbf{S}$.}

1984 L'Auca del Senyor Esteve. Barcelona, Edicions 62

\section{SEIFERT, A.}

1930 Bodenständige Gartenkunst, Gartenkunst, 43, 162164.

\section{VALLCORBA, J.}

1994 Noucentisme, Mediterraneisme $i$ Classicisme. Apunts per a la història d'una estètica. Barcelona, Quaderns Crema.

\section{VALLS I VICENS, J.M.}

1877 Algunes reflexions sobre la necessitat de la conservació y restabliment de las costums catalanas. Memòries de la Associació Catalanista d'Excursions Científicas, Volum III, 1887. 